\title{
Time-variable gravity field recovery from kinematic positions of Low Earth Orbiting satellites
}

\author{
Thomas Grombein, Martin Lasser, \\ Daniel Arnold, Ulrich Meyer, Adrian Jäggi
}

Astronomical Institute

University of Bern, Switzerland

Contact: thomas.grombein@aiub.unibe.ch

Citation: Grombein, T., Lasser, M., Arnold, D., Meyer, U., and Jäggi, A. (2021): Time-variable gravity field recovery from kinematic positions of Low Earth Orbiting satellites, EGU General Assembly, online, 19-30 Apr 2021, EGU21-7708, https://doi.org/10.5194/egusphere-egu21-7708

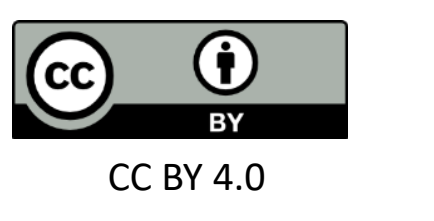




\section{Introduction}

- The Earth's time-variable gravity field

- Provides important information for monitoring changes in the Earth's system

- Dedicated satellite missions like GRACE/-FO use ultra-precise K-Band data (inter-satellite ranging) to derive time series of monthly gravity field solutions

- In addition: any Low Earth Orbiting (LEO) satellite equipped with an onboard GPS receiver may also serve as a gravity field sensor

- Gravity field recovery from kinematic LEO positions

- GPS-based kinematic LEO positions are purely geometrically determined and therefore suitable for gravity field recovery

- Although less sensitive, this technique provides mostly uninterrupted series

- Combined Multi-LEO gravity field solutions can take advantage of many observations and the variety of complementary orbital configurations
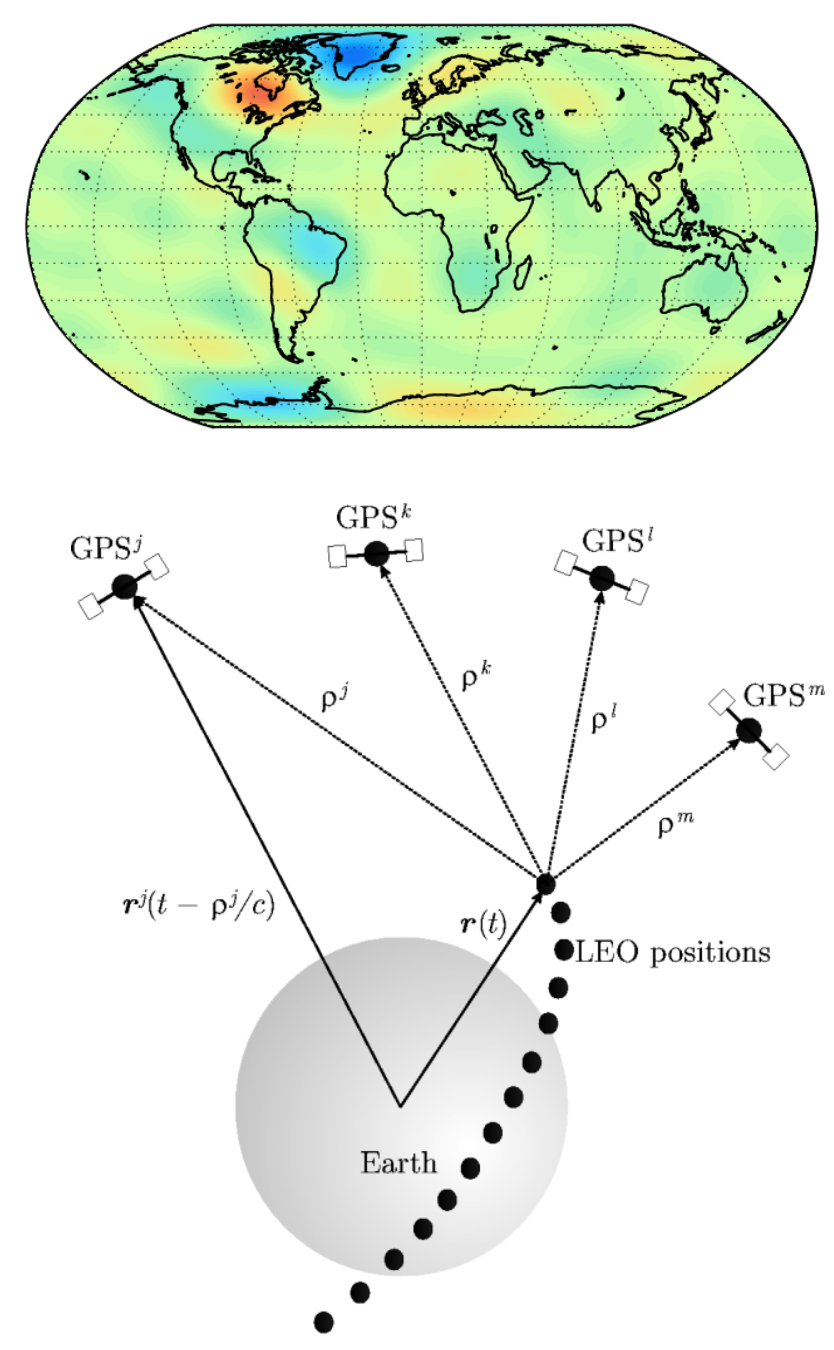


\section{GPS-based orbit and gravity field determination}

\section{- Precise orbit determination}

- GPS-based kinematic orbits are routinely processed at AIUB for various LEO satellites like GRACE/-FO, GOCE, SWARM, Sentinel, ...

- Bernese GNSS Software with GNSS products of CODE

- In-flight calibrated phase center variation (PCV) maps

- Ambiguity-float and nowadays also ambiguity-fixed orbit solutions

- Gravity field processing (Celestial Mechanics Approach)

- Kinematic LEO positions are used as pseudo-observations in a generalized orbit determination problem

- Orbit and gravity field parameters are estimated simultaneously

- Unmodeled forces are absorbed by empirical/stochastic parameters
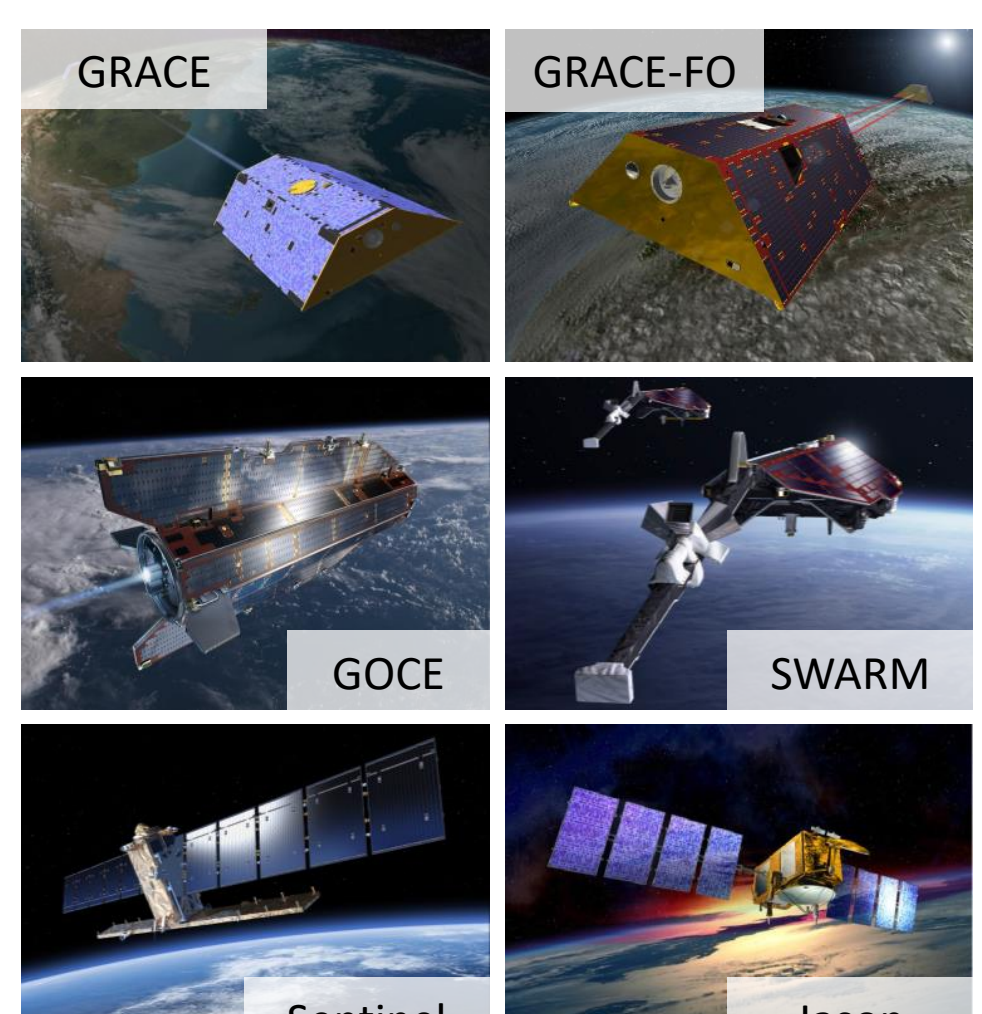

Sentinel

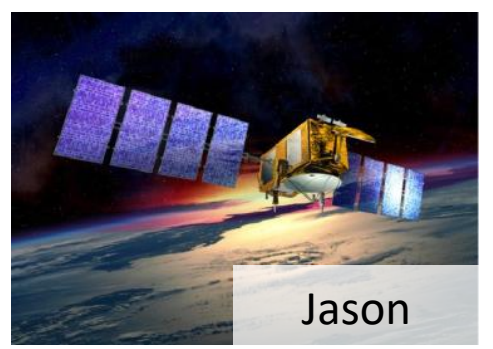

Source: ESA, NASA 


\section{Gravity field processing}

- Focus of this talk: GRACE/-FO GPS-only solutions

\begin{tabular}{|c|c|c|}
\hline & GRACE & GRACE-FO \\
\hline Processing period & $2009 / 01-2017 / 10$ & $2018 / 06-2021 / 02$ \\
\hline Kinematic orbit & ambiguity-float & ambiguity-fixed \\
\hline Data sampling & 6 orbital elements (daily) \\
\hline Initial conditions & \multicolumn{2}{|c|}{-} \\
\hline Empirical parameters & Piecewise constant accelerations (15 min) \\
\hline Stochastic parameters & Yes / Bias and Scaling factors (daily) \\
\hline Accelerometer data & d/o 90 (monthly) \\
\hline Gravity field coefficients &
\end{tabular}

- Further used GPS-only solutions

\begin{tabular}{|c|c|}
\hline $\begin{array}{c}\text { GOCE } \\
\text { (Arnold et al. 2021) }\end{array}$ & $\begin{array}{c}\text { SWARM } \\
\text { (Dahle et al. 2017) }\end{array}$ \\
\hline $\begin{array}{c}\text { 2009/11 - 2013/10 } \\
\text { ambiguity-float }\end{array}$ & 2013/12 - 2020/12 \\
\hline $1 \mathrm{~s}$ & $10 / 5 \mathrm{~s}$ \\
\hline $\begin{array}{c}\text { ambiguity-float } \\
\text { orbital elements (daily) } \\
\text { Constant and 1/per rev } \\
\text { accelerations (daily) } \\
\text { Pseudo-stochastic pulses } \\
\text { (6 min) }\end{array}$ & $\begin{array}{c}\text { Constant accelerations } \\
\text { (daily) }\end{array}$ \\
$\begin{array}{c}\text { Pes / - } \\
\text { accelewise constant }\end{array}$ \\
d/o 120 (monthly) & d/o 40, 70 (monthly) \\
\hline
\end{tabular}

- Monthly ITSG-Grace2018 / ITSG-Grace_op solutions are used as reference (Mayer-Gürr et al. 2018) 


\section{GRACE GPS-only gravity field solutions}


GRACE GPS-only gravity field solutions

Quality of monthly GRACE GPS-only gravity field solutions

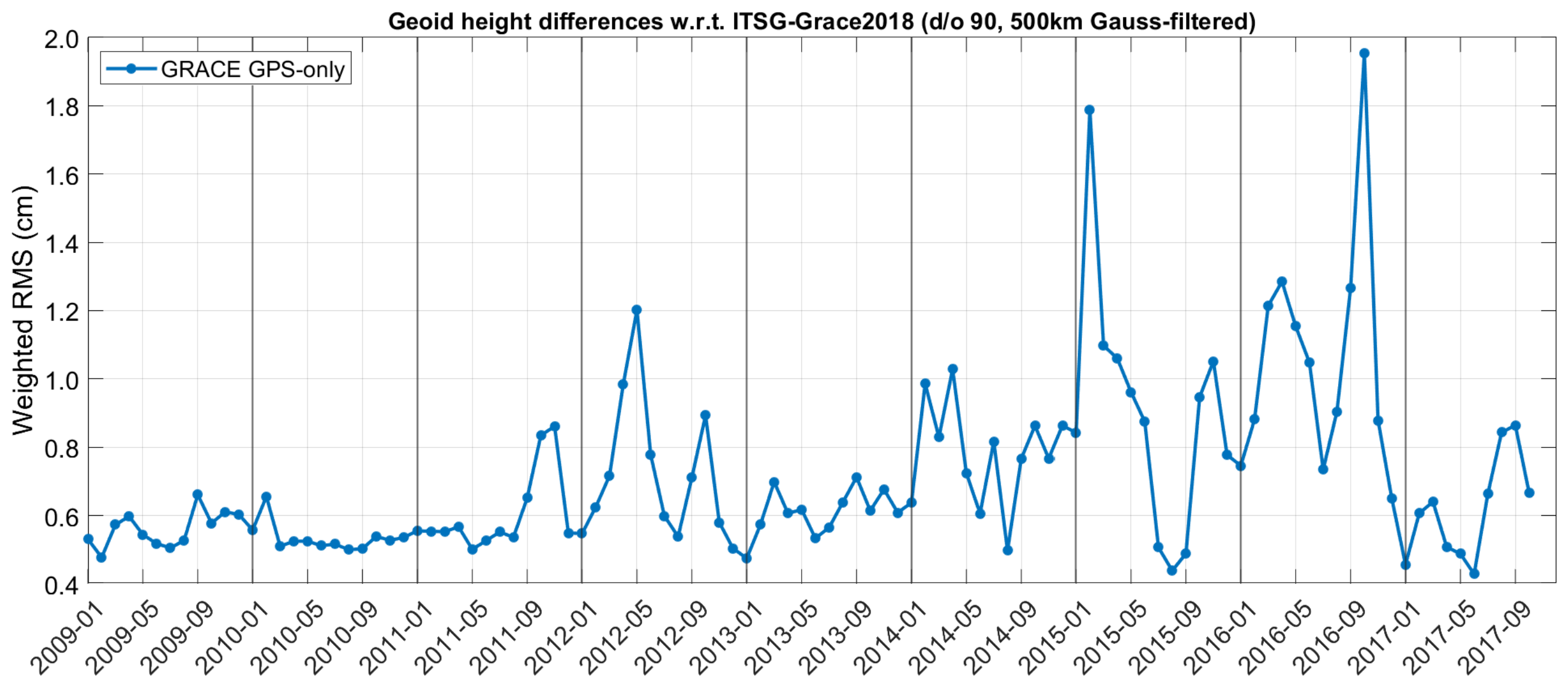

Slide 6

Astronomical Institute, University of Bern $A \boldsymbol{U} \boldsymbol{B}$ 


\section{GRACE GPS-only gravity field solutions}

- Quality of monthly GRACE GPS-only gravity field solutions

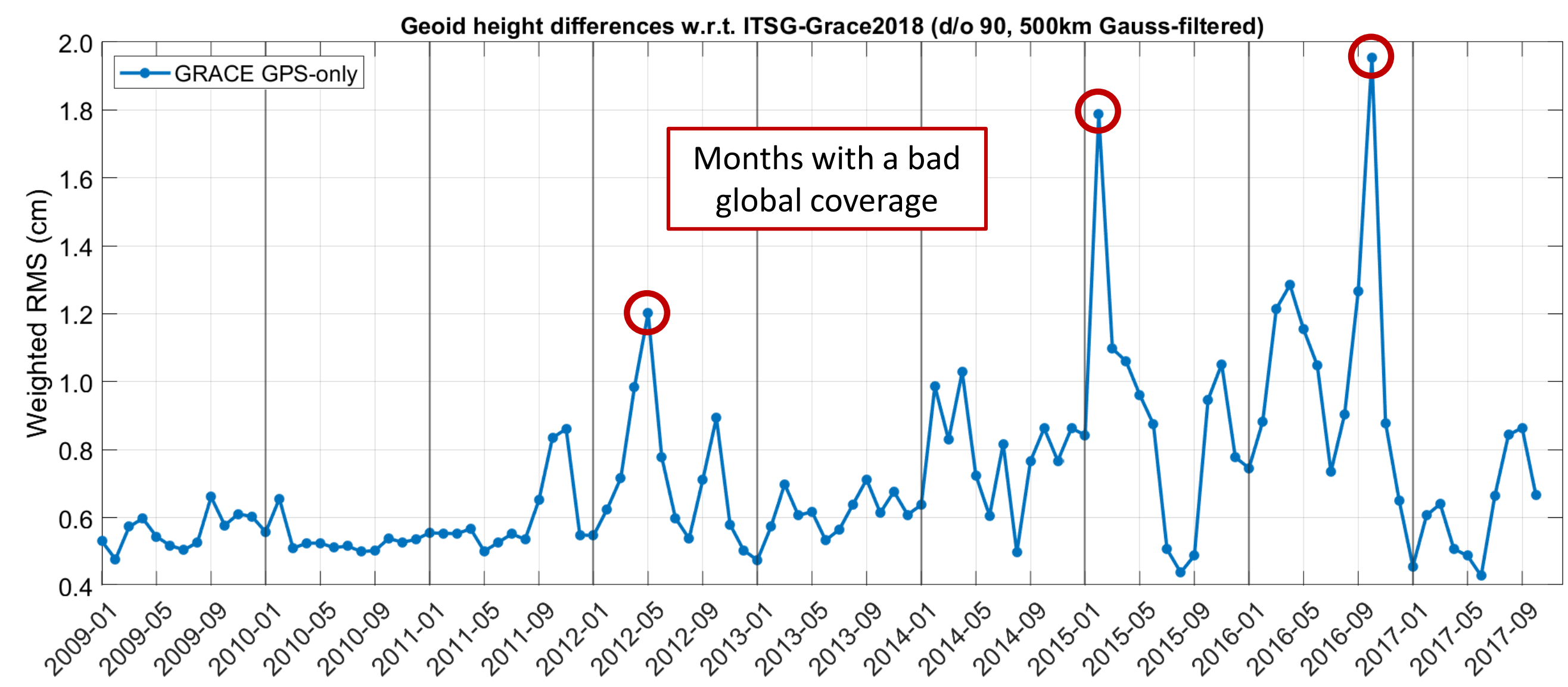




\section{GRACE GPS-only gravity field solutions}

- Quality of monthly GRACE GPS-only gravity field solutions

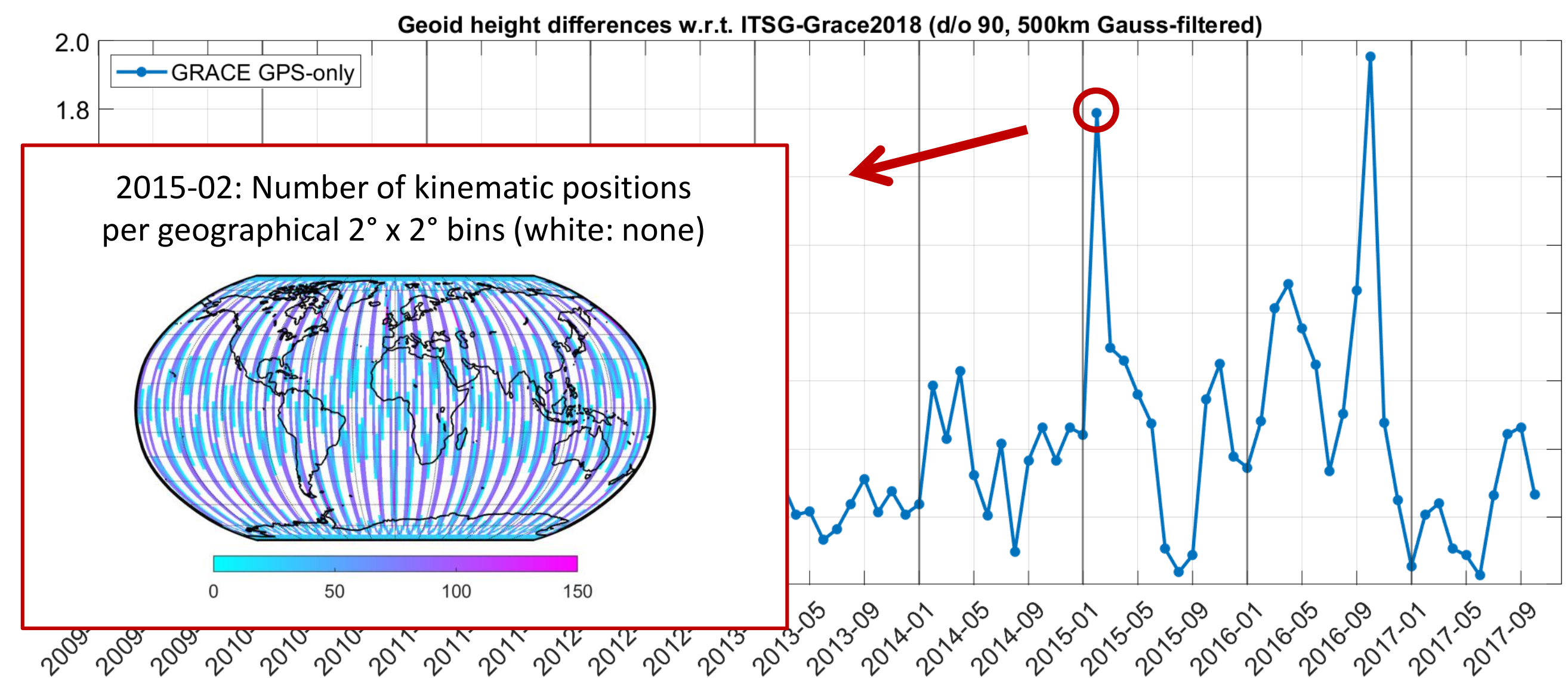




\section{GRACE GPS-only gravity field solutions}

- Correlation with the ionospheric activity represented by the global mean total electron content (TEC)

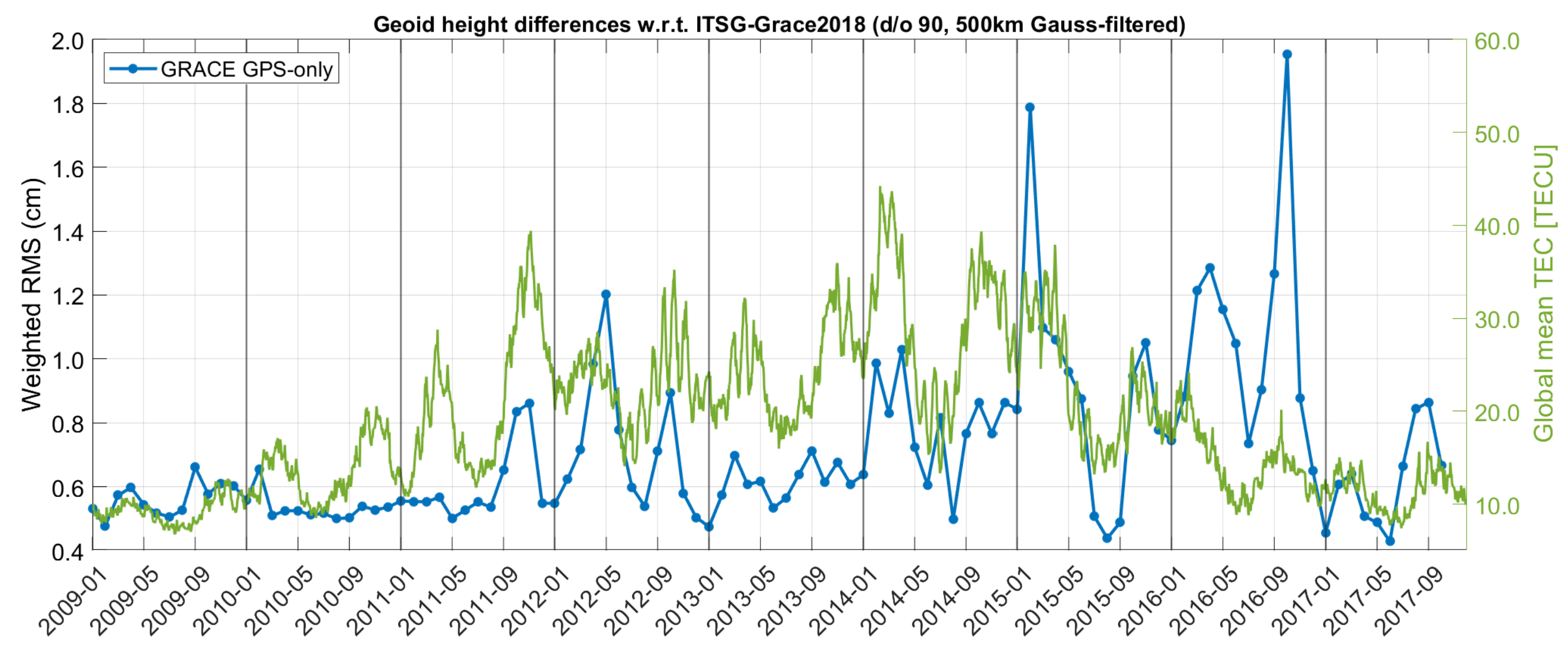




\section{Effects of ionospheric disturbances}

- Degradation of kinematic positions directly propagates into GPS-only gravity field solutions

- Artifacts along the geomagnetic equator, known from GOCE / SWARM, are also visible for GRACE
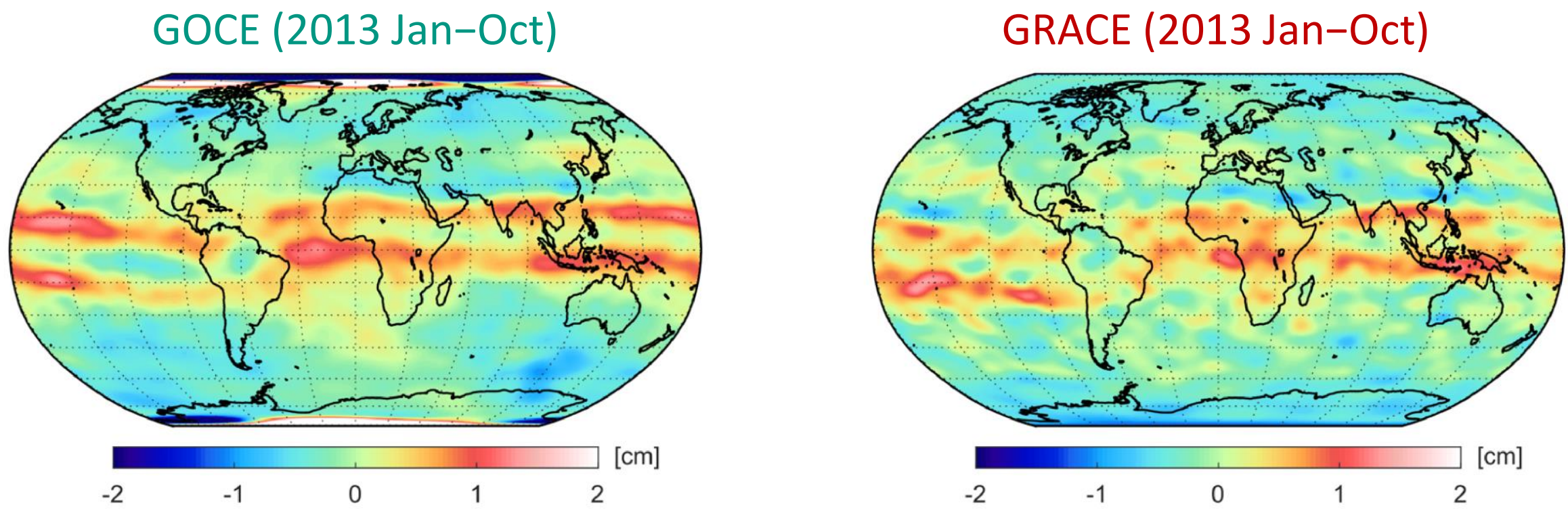

Geoid height differences w.r.t. ITSG-Grace2018

(500 km Gauss-filtered) 


\section{GRACE-FO GPS-only gravity field solutions}




\section{GRACE-FO GPS-only gravity field solutions}

- Quality of monthly GRACE-FO GPS-only gravity field solutions

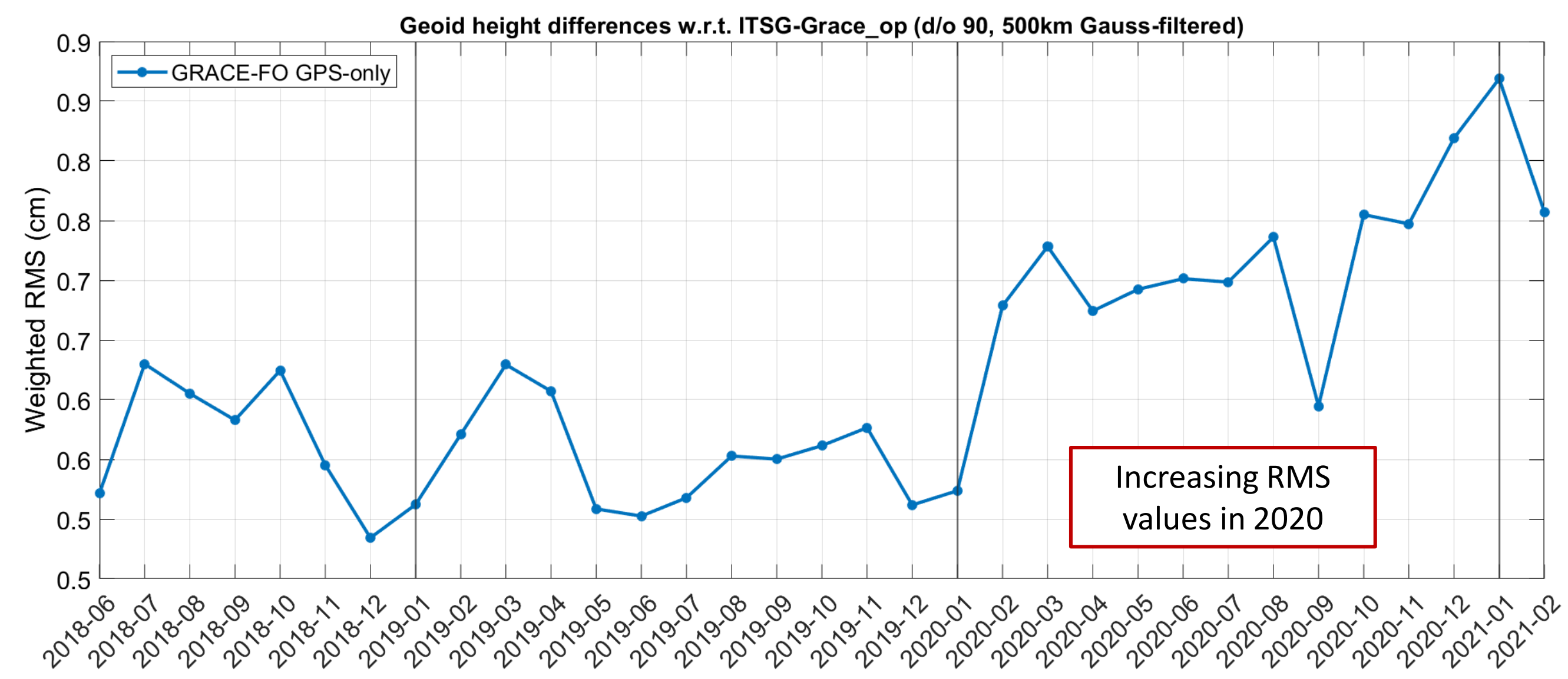




\section{GRACE-FO GPS-only gravity field solutions}

- Activated GPS Flex Power affects the orbit and gravity field quality (under investigation)

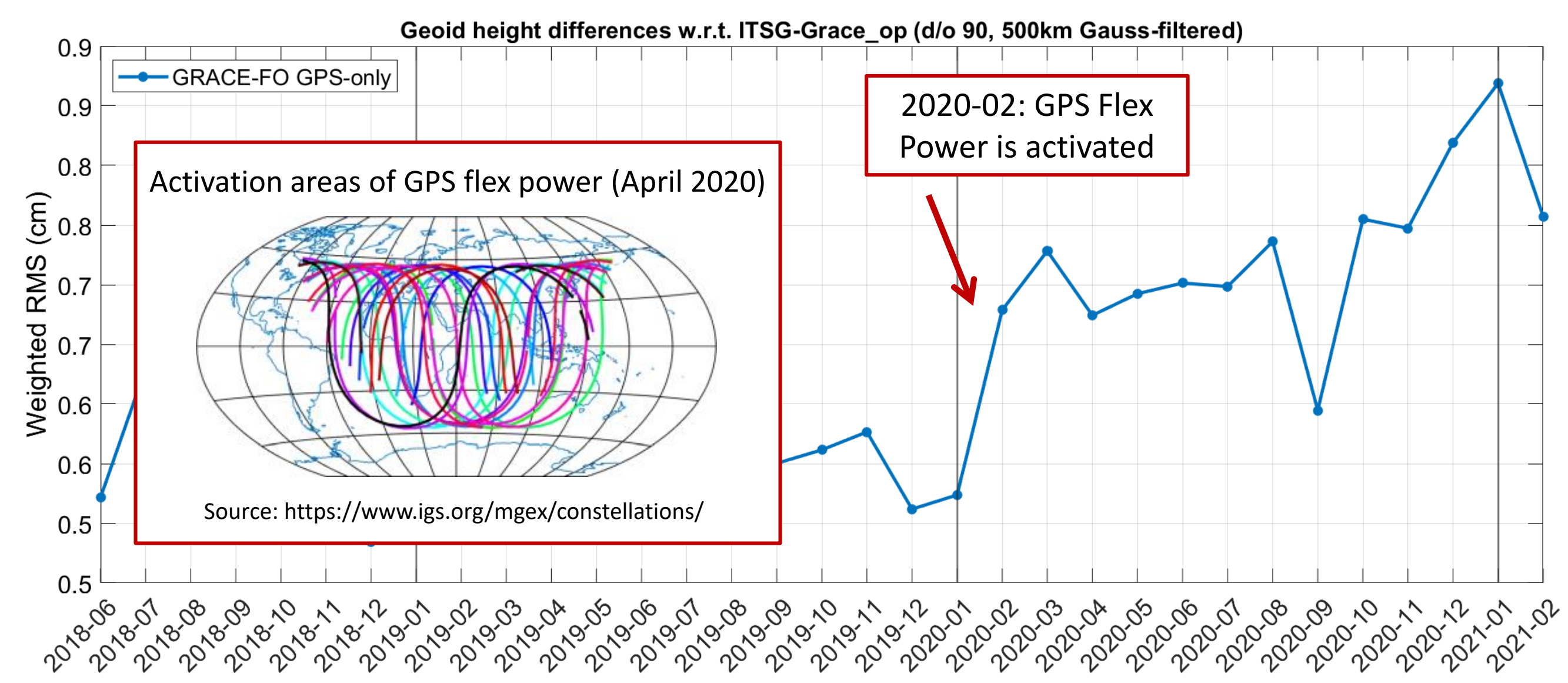




\section{GRACE-FO GPS-only gravity field solutions}

- Comparison of accumulated yearly solutions for 2019 and 2020
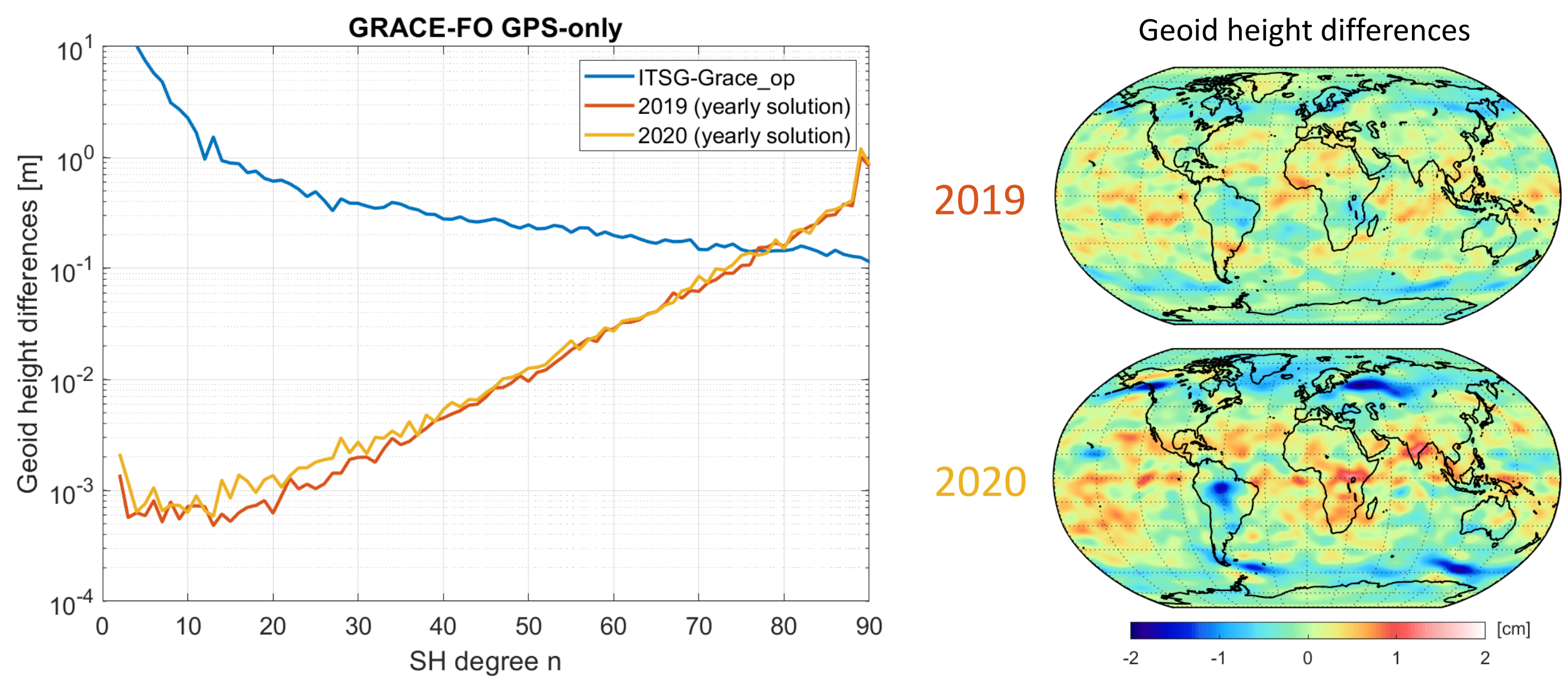


\section{GRACE-FO GPS-only gravity field solutions}

- Comparison of accumulated yearly solutions for 2019 and 2020
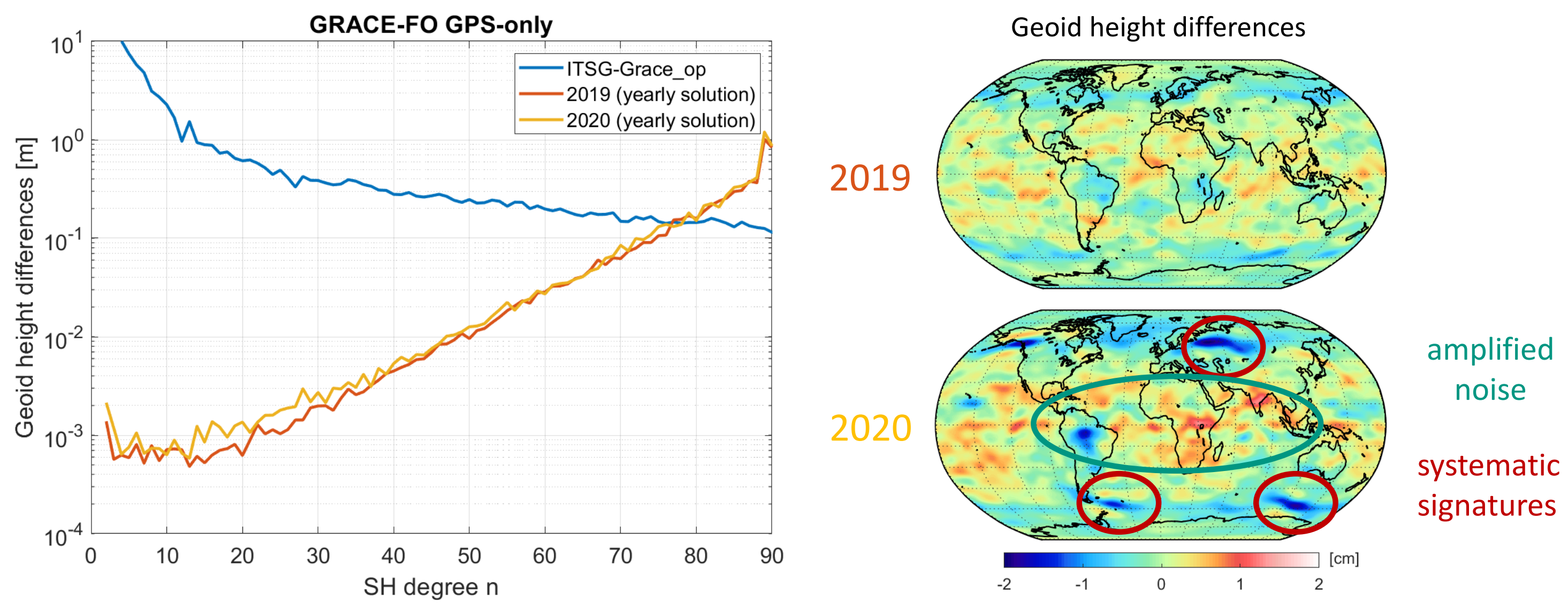


\section{GRACE-FO GPS-only gravity field solutions}

- Correlation with TEC values might also be seen for GRACE-FO (but much lower ionospheric activity)

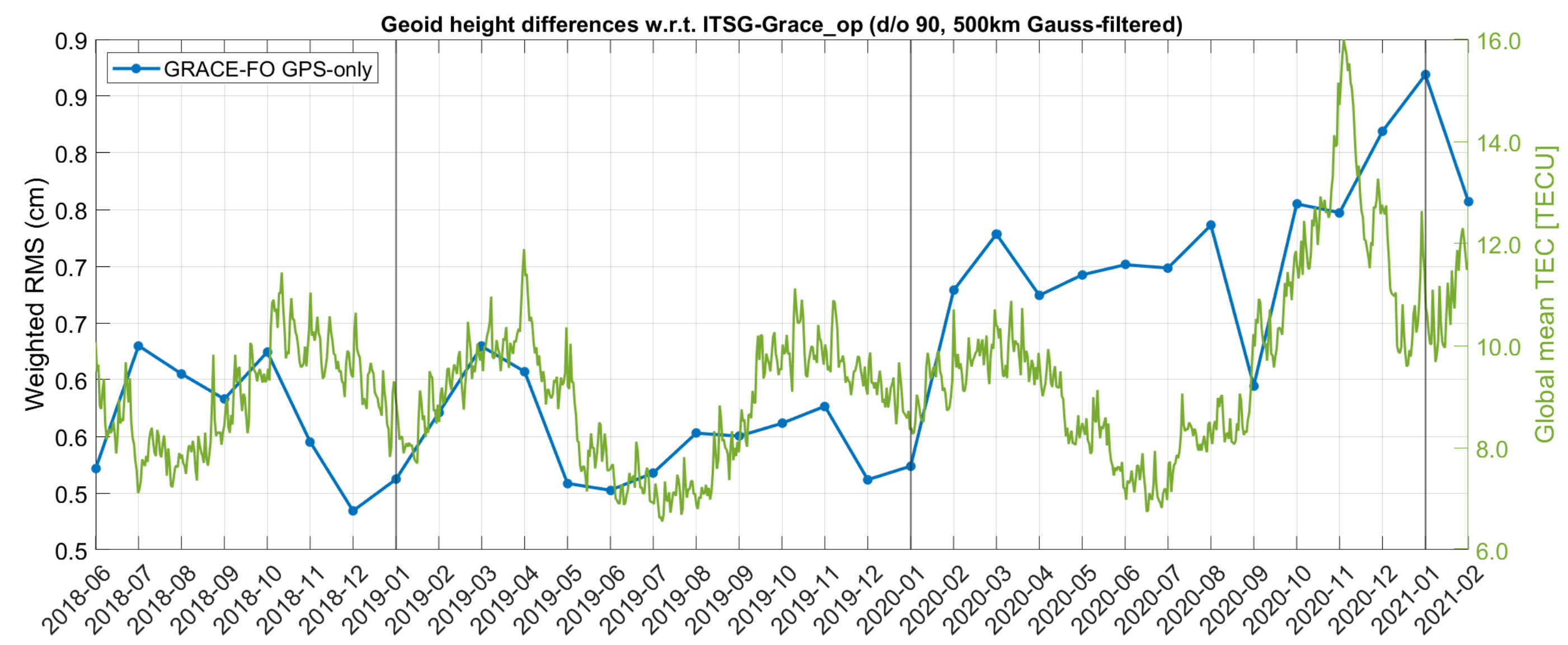




\section{Evaluation of mass trends and changes}




\section{Evaluation of mass trends and changes}

- Time series of monthly GPS-only solutions are used for the evaluation of mass trends and changes

- Analysis of mean equivalent water height $(E W H)$ values averaged over selected regions

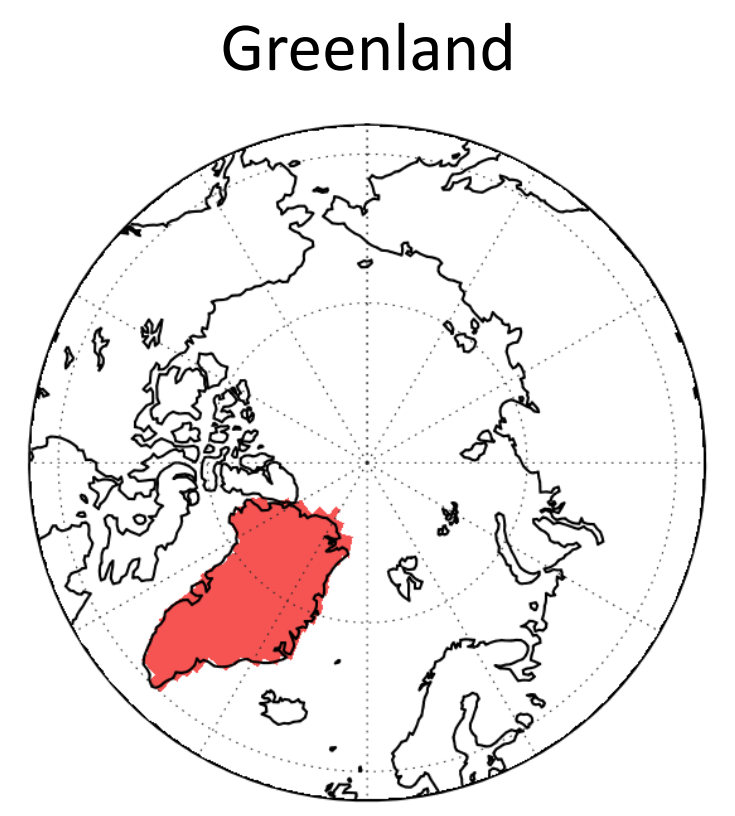

Amazon river basin

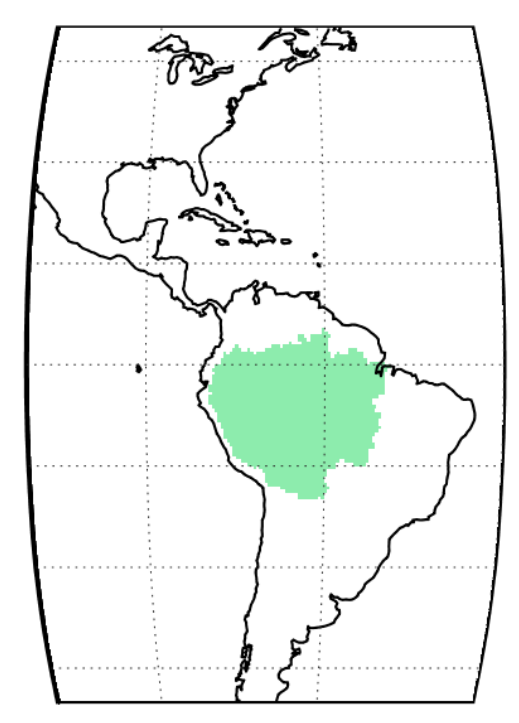

West/East-Antarctica

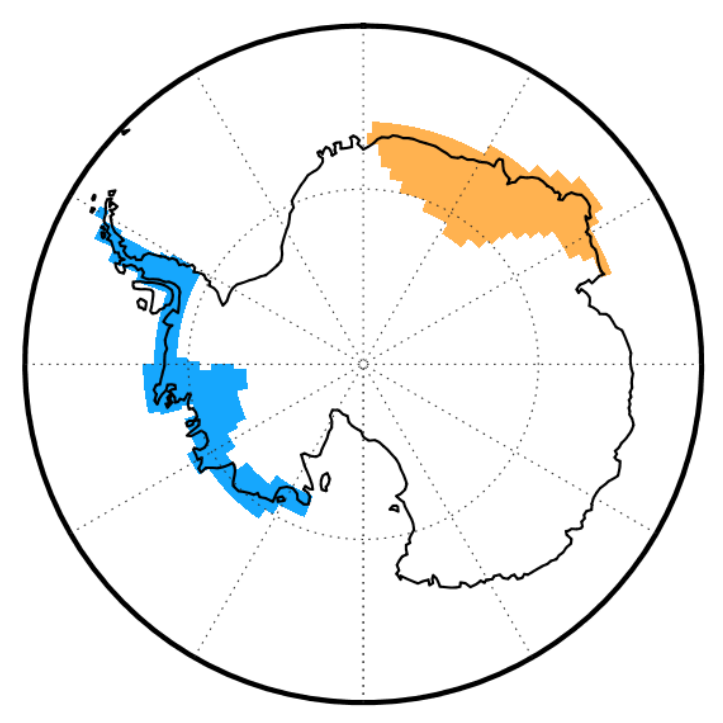




\section{Evaluation of mass trends and changes: GRACE GPS-only}

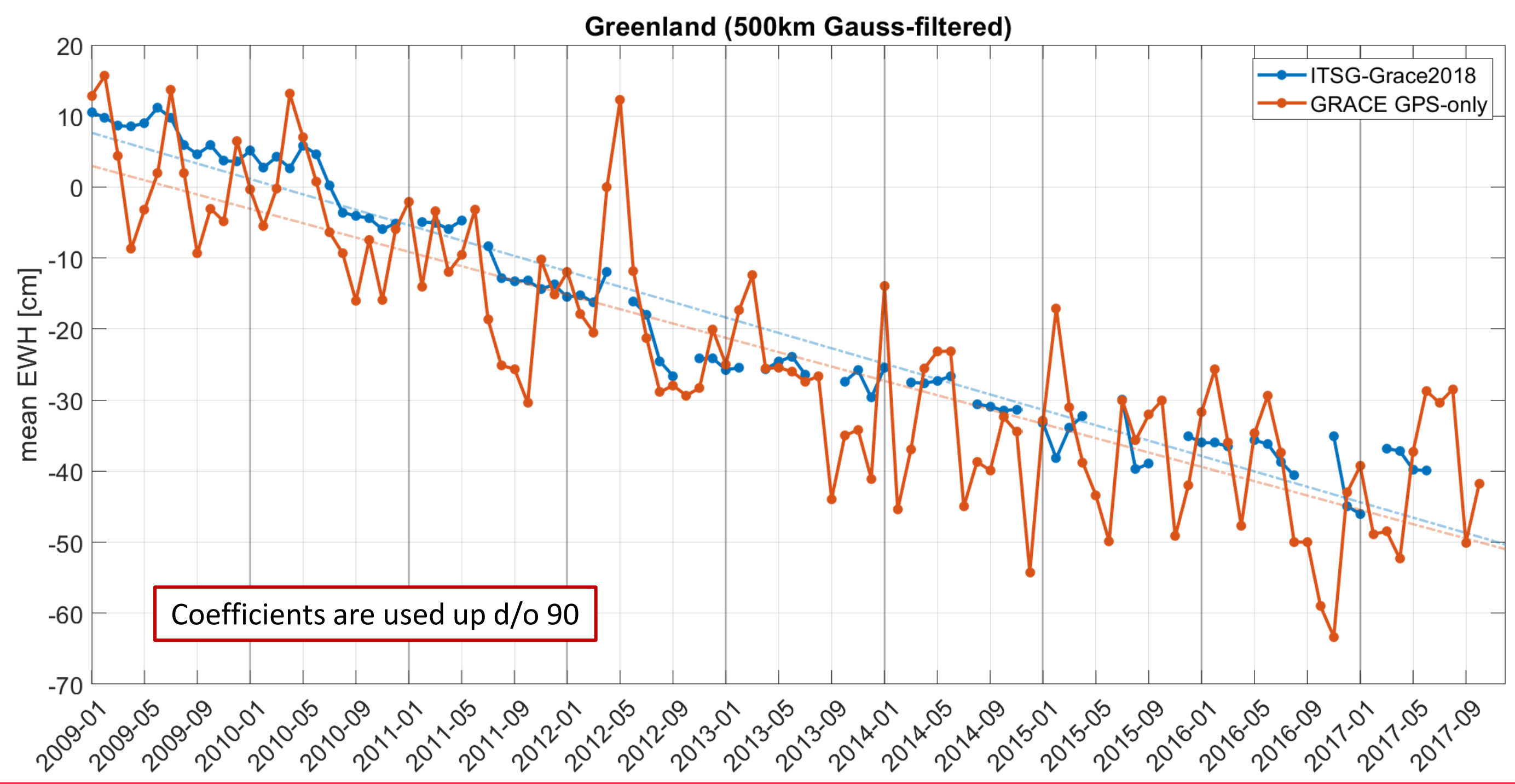




\section{Evaluation of mass trends and changes: GRACE GPS-only}

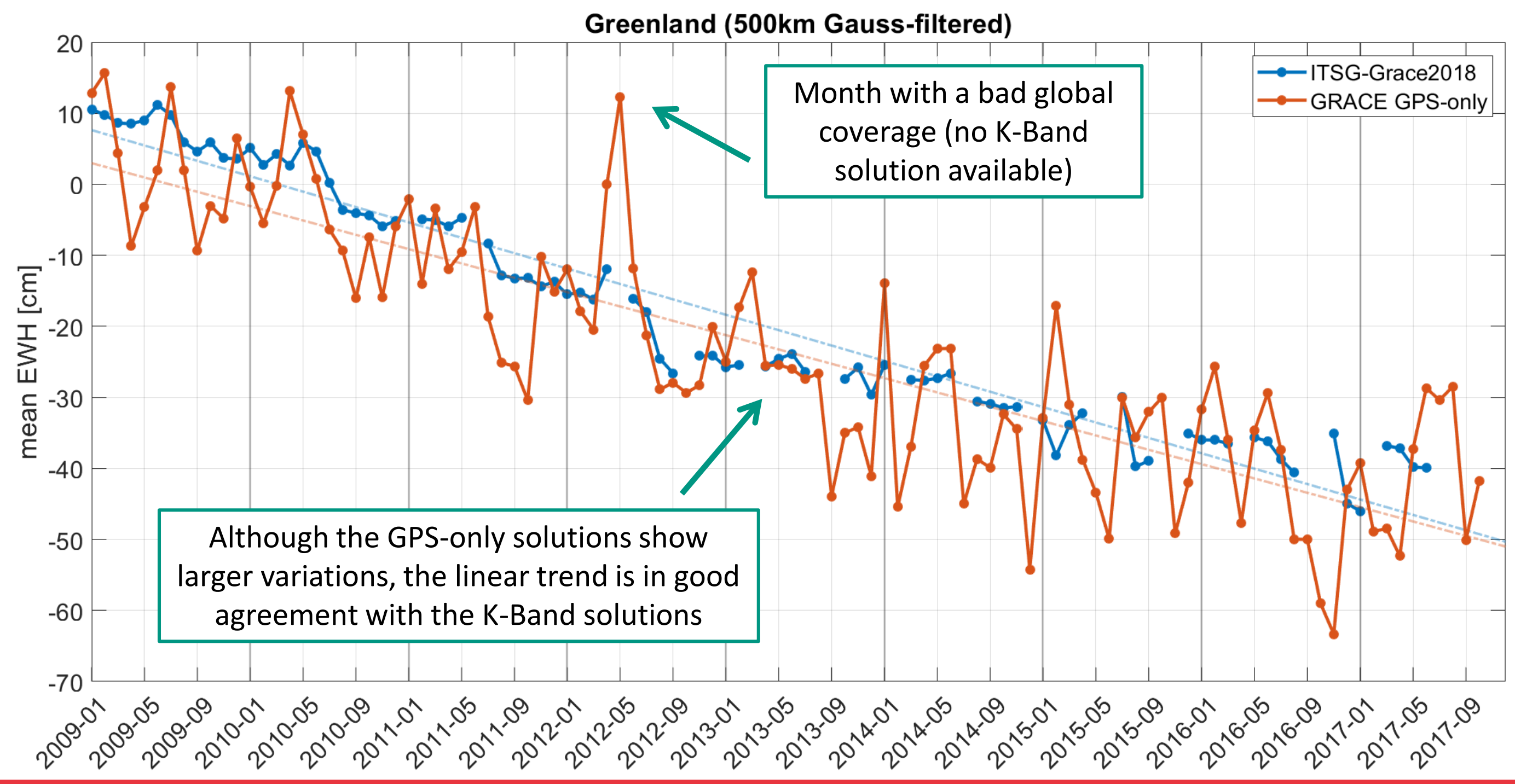




\section{Evaluation of mass trends and changes: GRACE GPS-only}

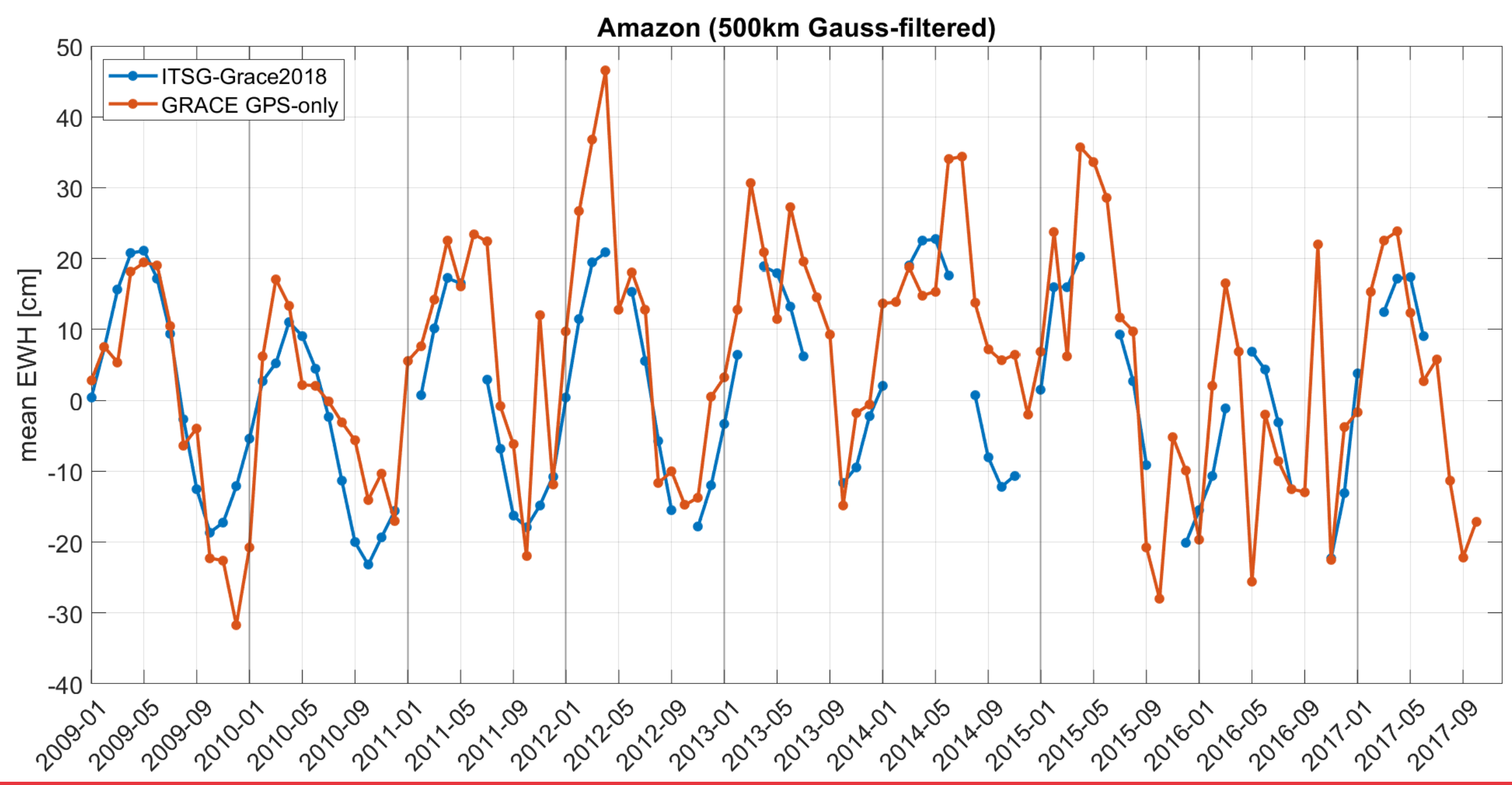




\section{Evaluation of mass trends and changes: GRACE GPS-only}

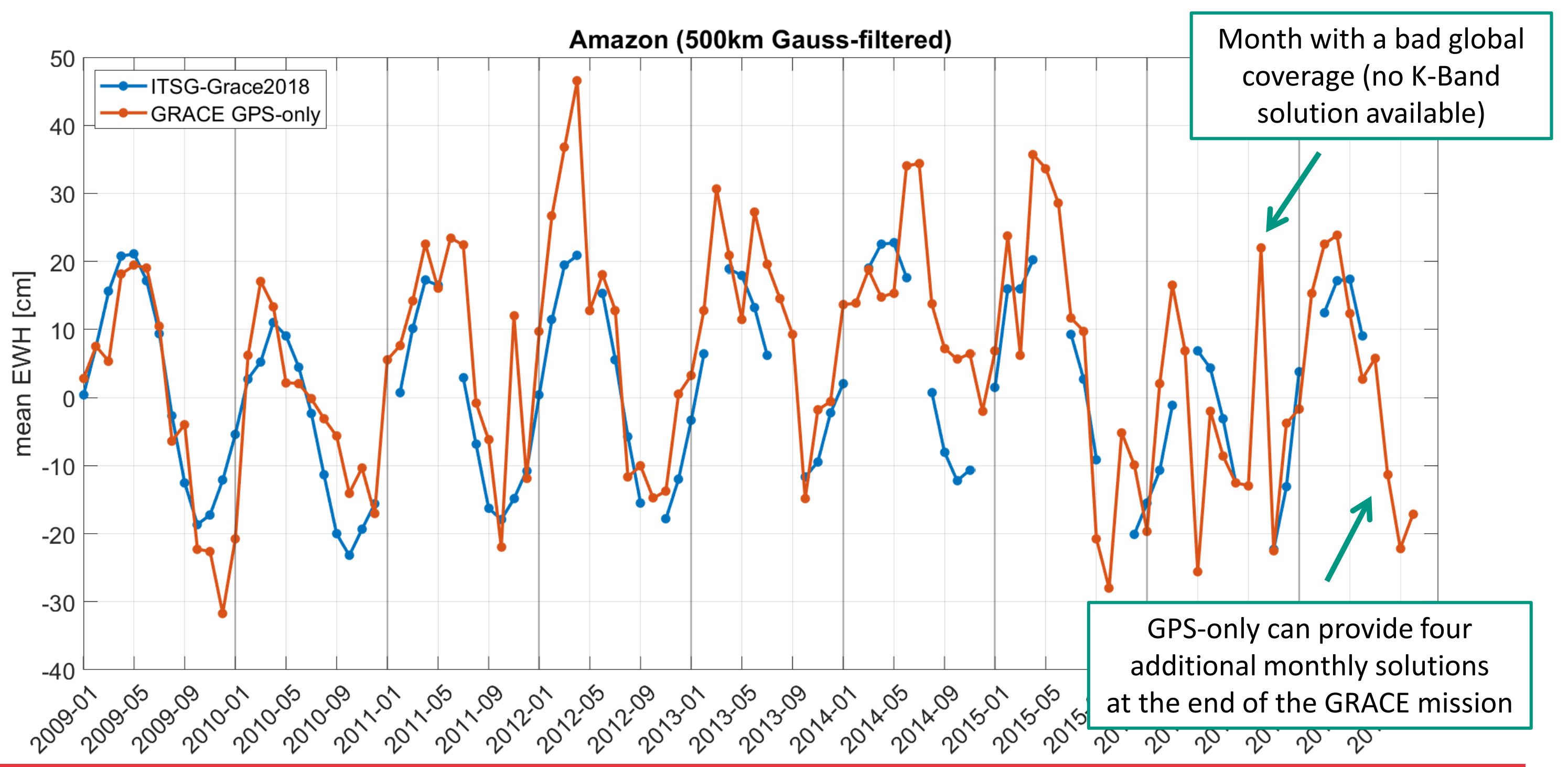




\section{Evaluation of mass trends and changes: GRACE GPS-only}

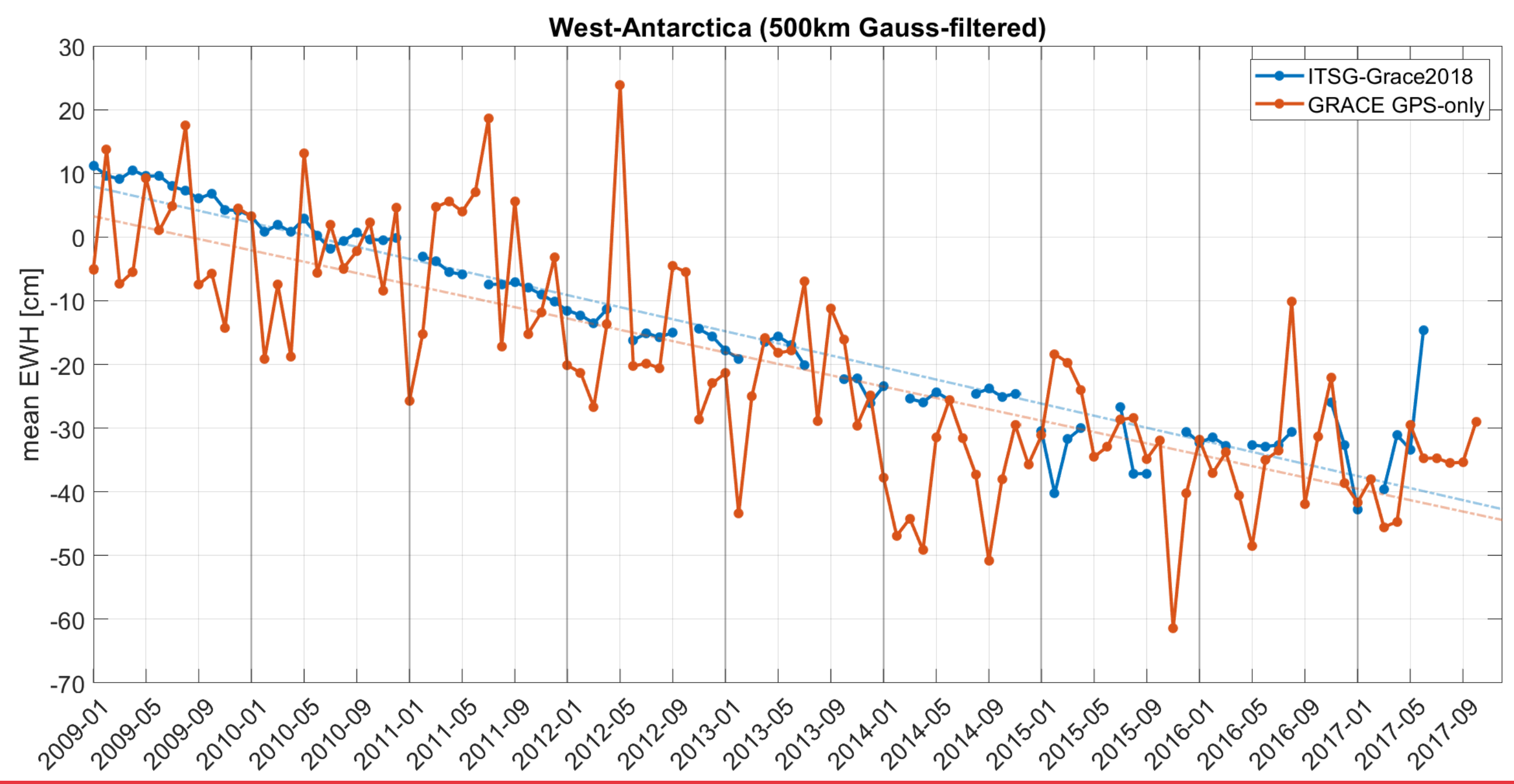




\section{Evaluation of mass trends and changes: GRACE-FO GPS-only}

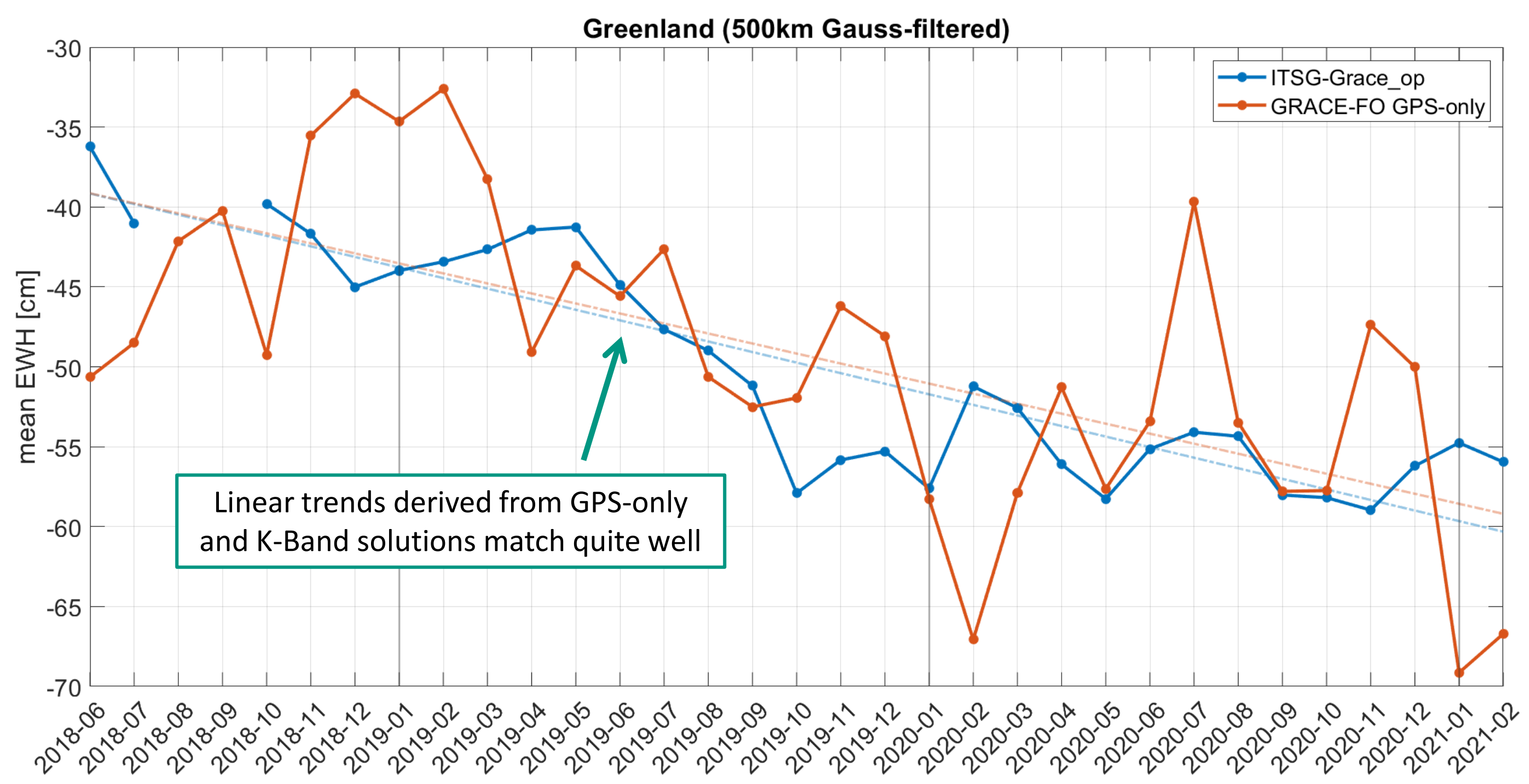




\section{Evaluation of mass trends and changes: GRACE-FO GPS-only}

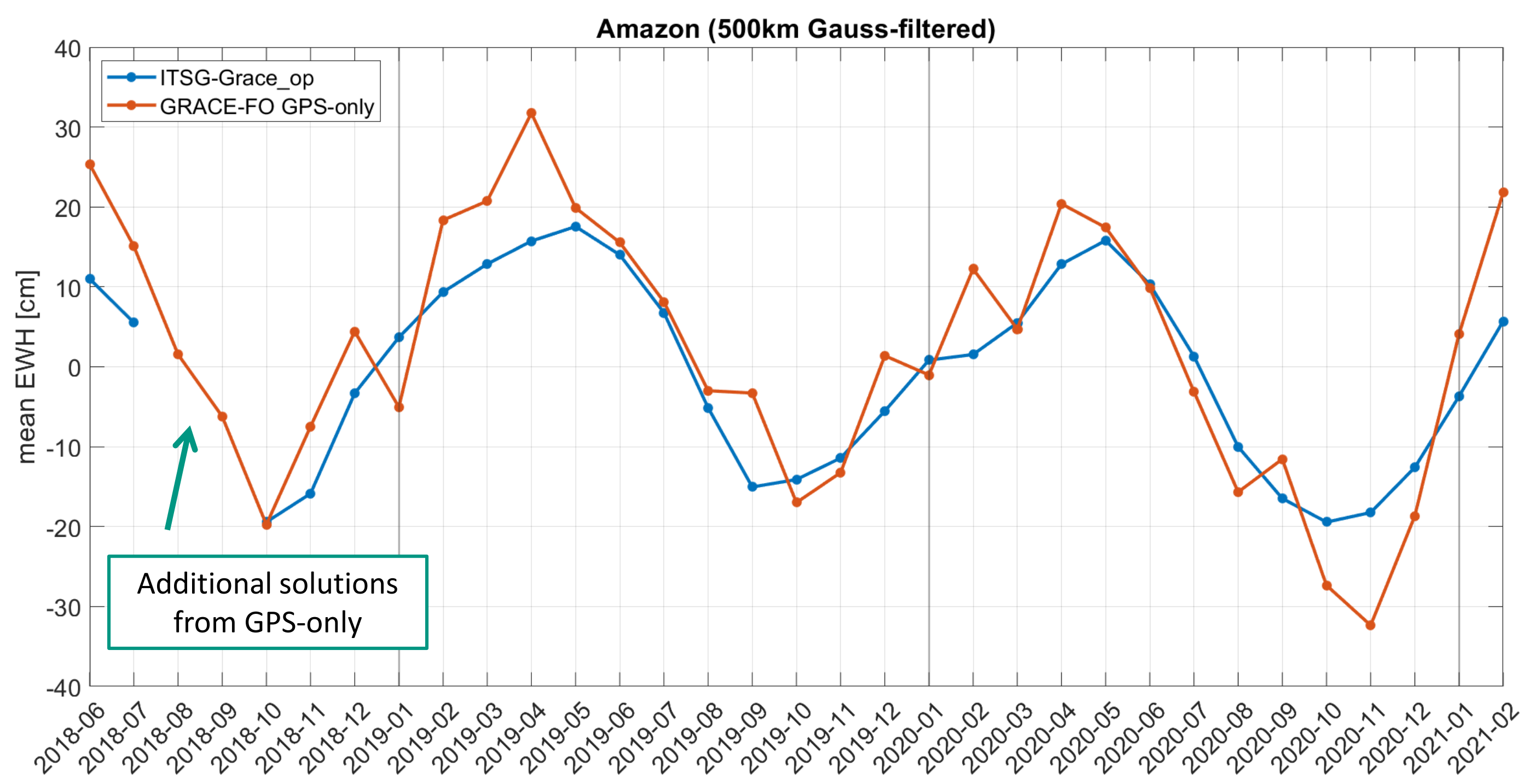




\section{Evaluation of mass trends and changes: GRACE-FO GPS-only}

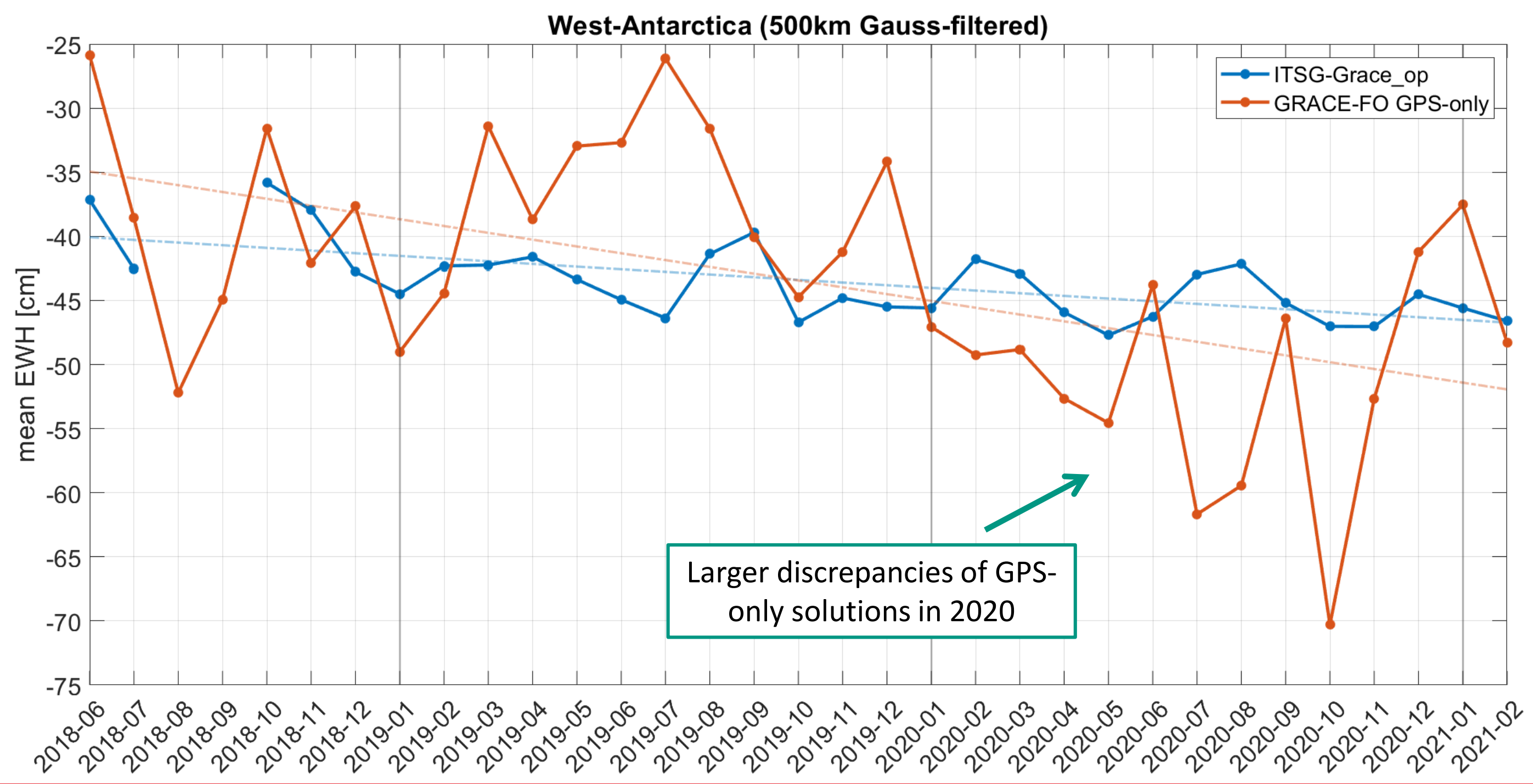




\section{Comparisons to time series of other LEOs}




\section{Evaluation of mass trends and changes: Comparison to other LEOs}

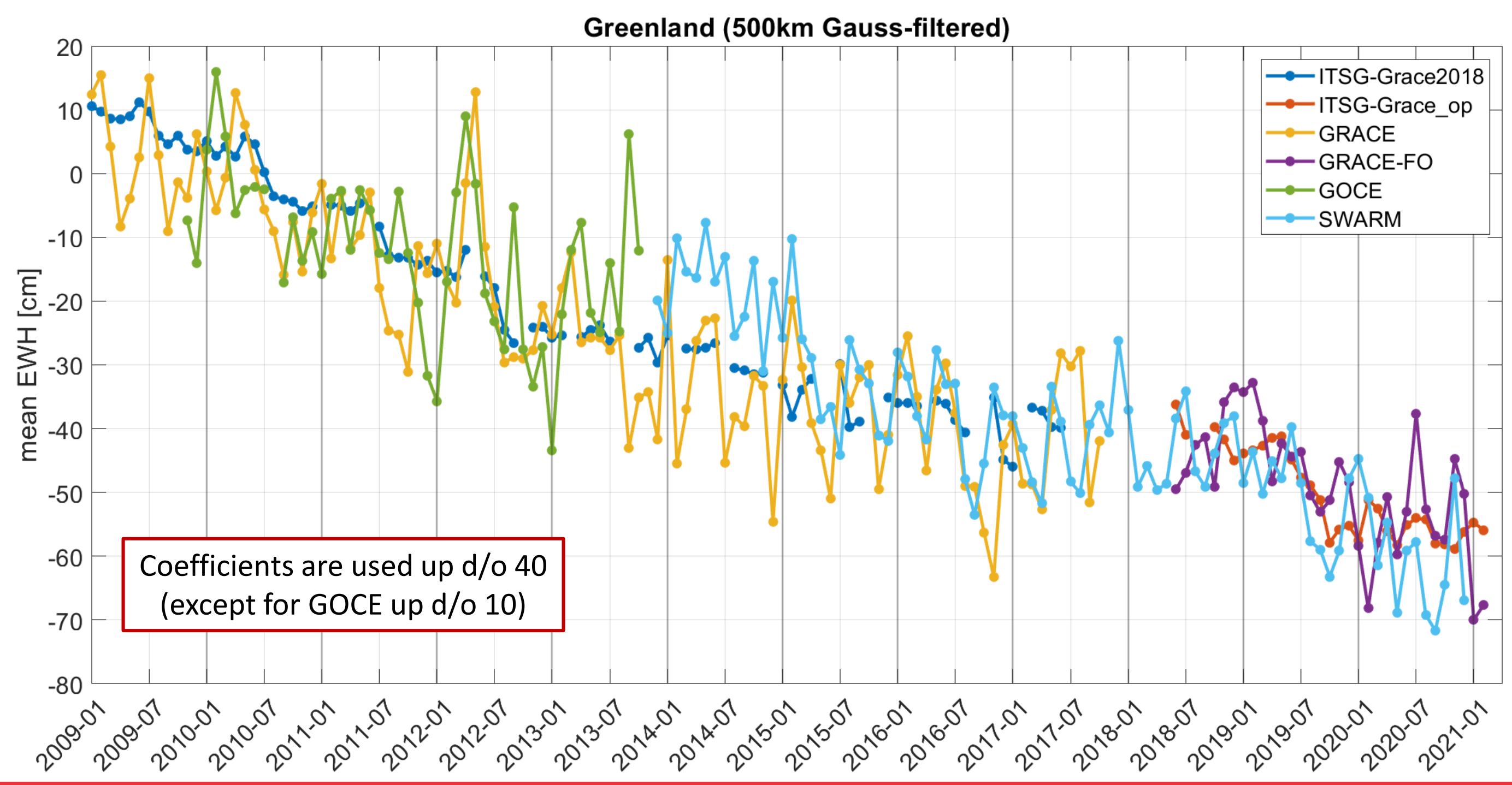




\section{Evaluation of mass trends and changes: Comparison to other LEOs}

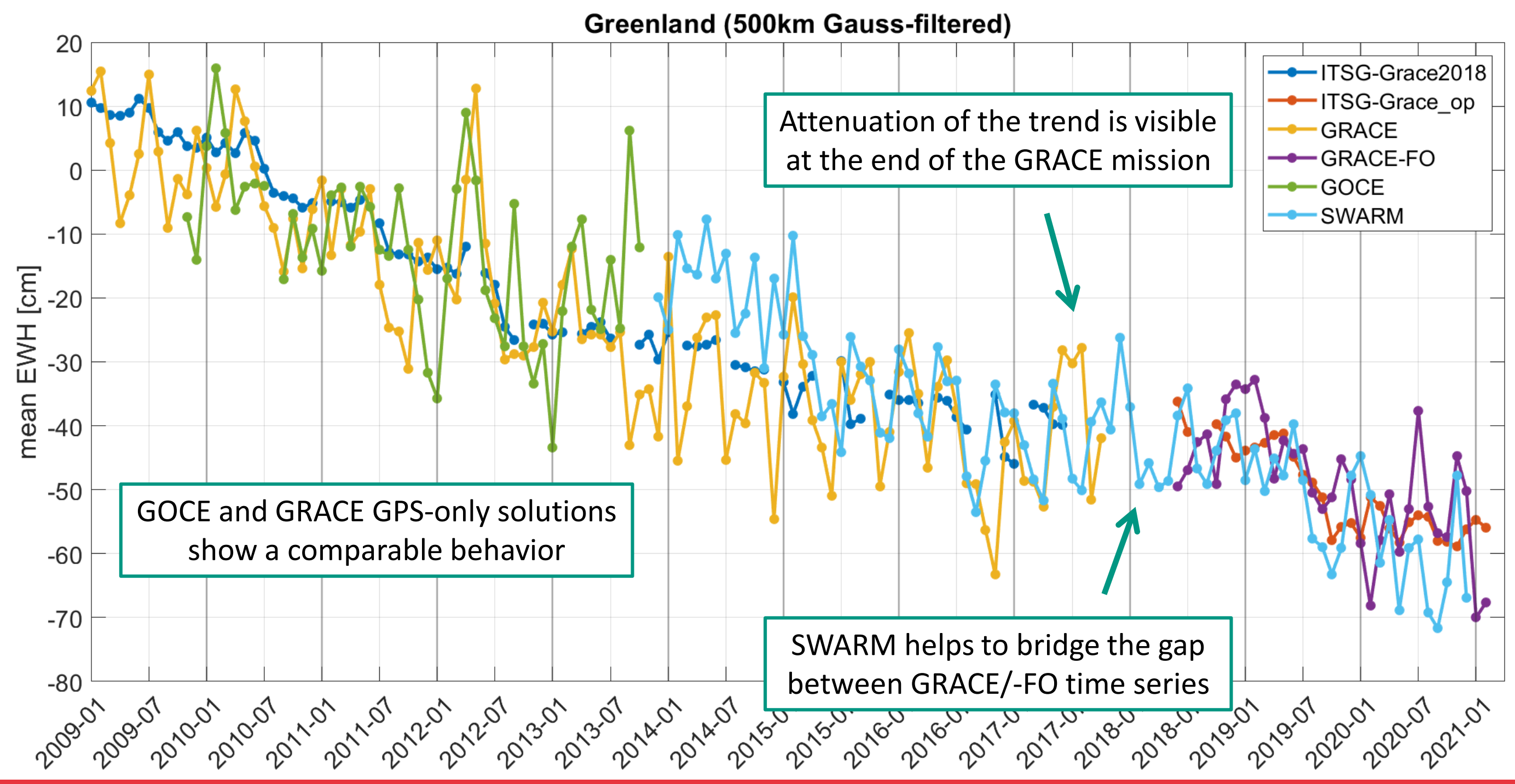




\section{Evaluation of mass trends and changes: Comparison to other LEOs}

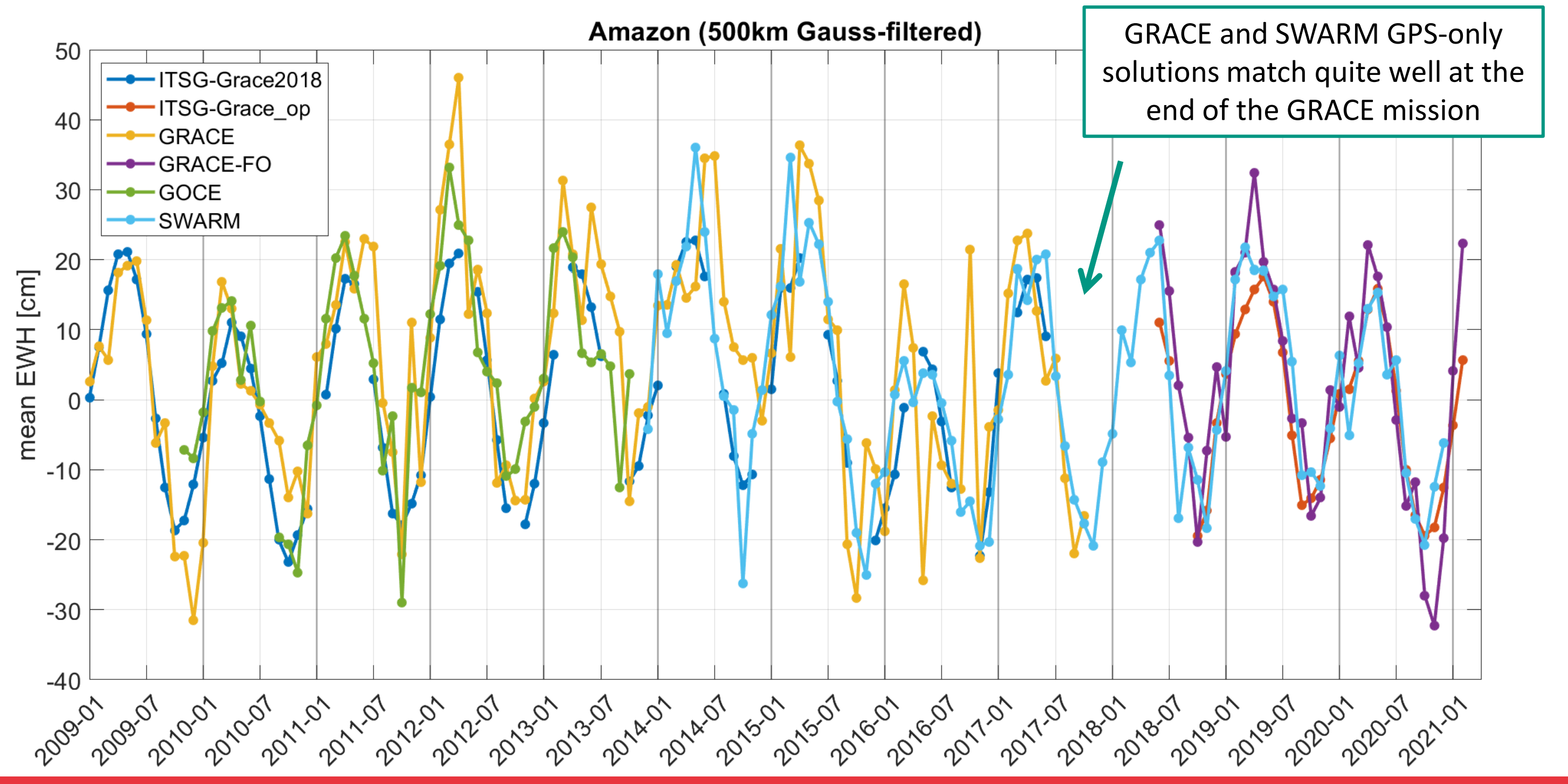




\section{Evaluation of mass trends and changes: Comparison to other LEOs}

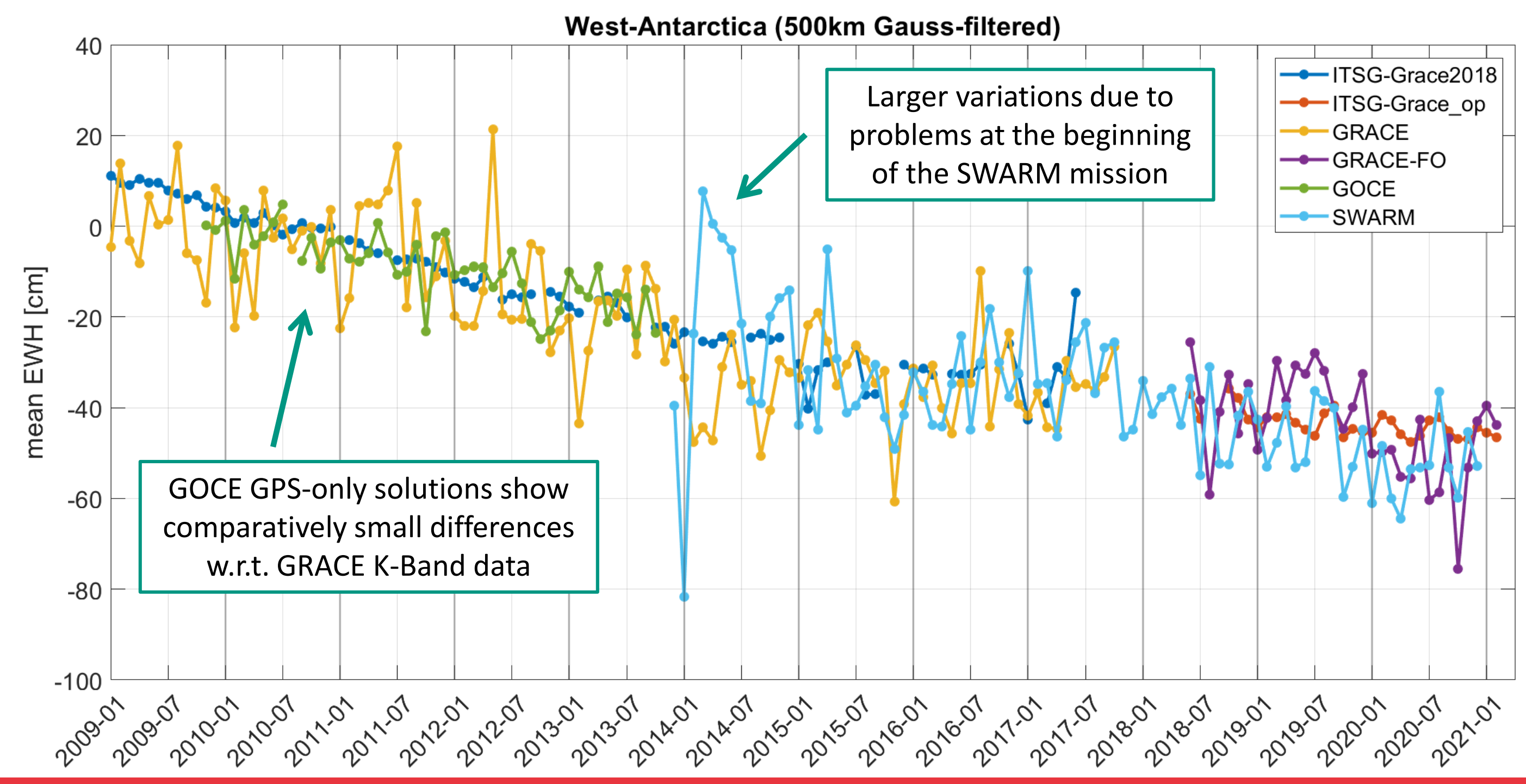




\section{Evaluation of mass trends and changes: Comparison to other LEOs}

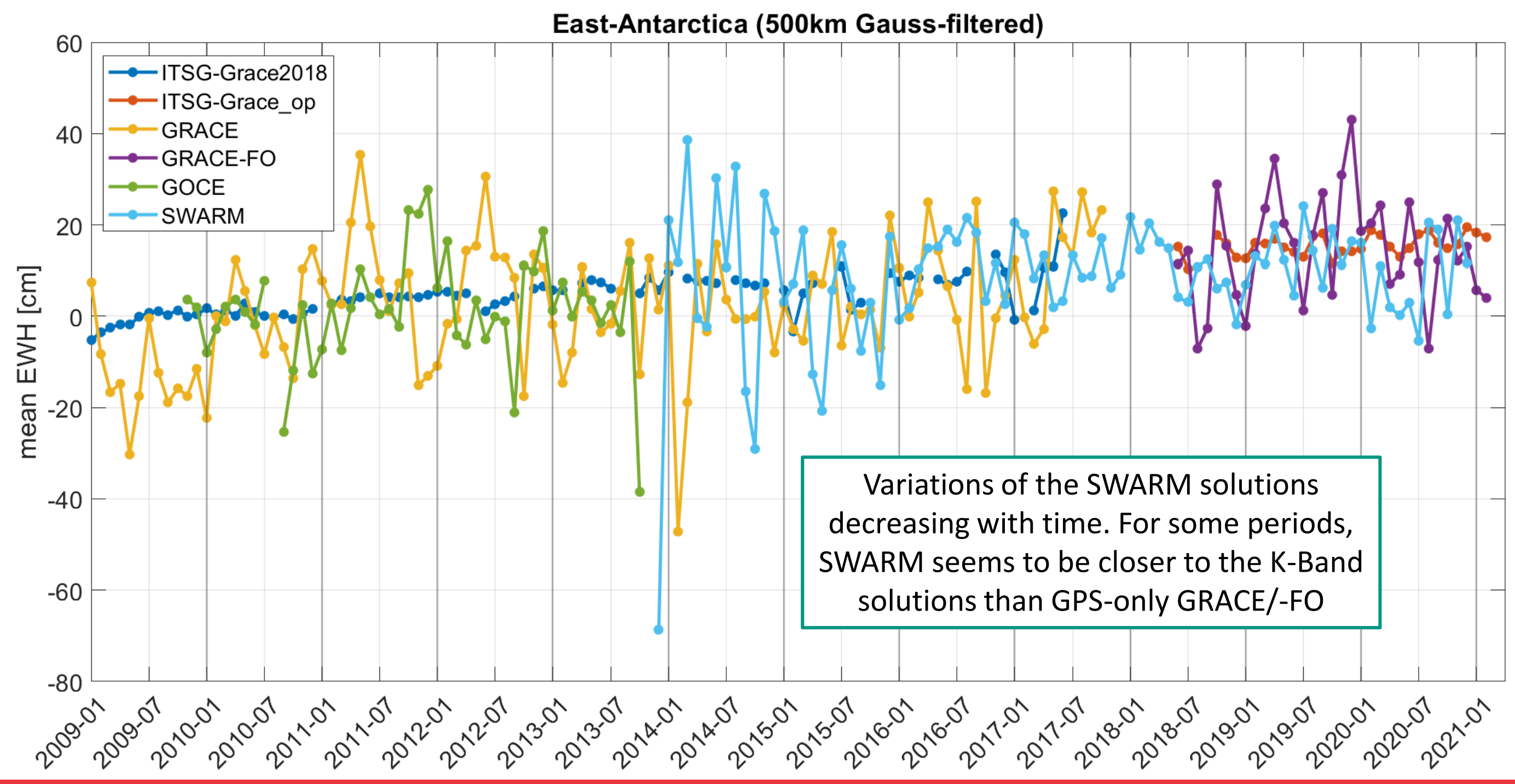


Estimation of trends and annual variations (Jan 2009 - Oct 2017)

- A posteriori fit of monthly gravity field solutions (up to $\mathrm{d} / \mathrm{o} 10$ )

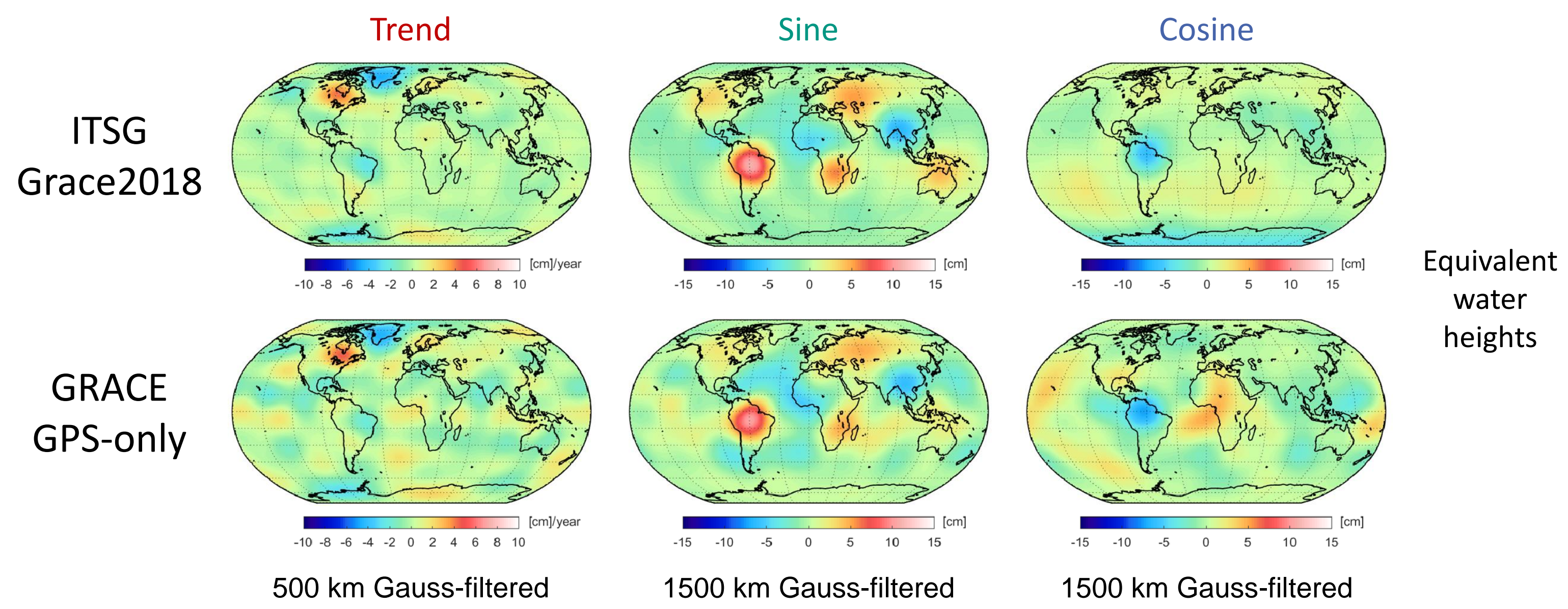




\section{Summary and Outlook}

- Time-variable gravity field recovery from kinematic LEO positions

- Processing of time series of monthly gravity field solution from

- 8.8 years of GRACE GPS data (2009/01 - 2017/10)

- 2.8 years of GRACE-FO GPS data (2018/06 - 2021/02)

- Major mass trends and changes in Greenland, Antarctica and the Amazon river basin are in good agreement with those derived from inter-satellite ranging (however: as expected GPS-only solutions exhibit larger variations)

- Comparisons to time series based on GOCE and SWARM GPS data are promising in the view of future combinations

- Next steps

- Extension of the monthly GRACE and GRACE-FO time series

- Combined time series based on kinematic orbits of multiple LEO satellites
GRACE
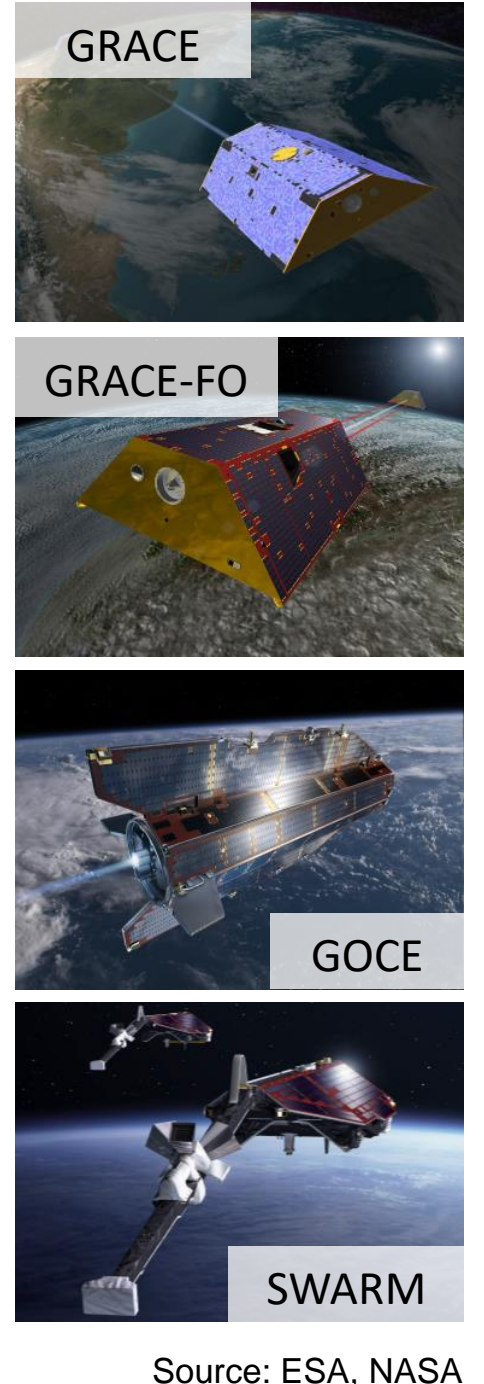


\section{References}

Arnold D, Grombein T, Schreiter L, Sterken V, Jäggi A (2021): Reprocessed precise science orbits and gravity field recovery for the entire GOCE mission (Publication in preparation)

Dahle C, Arnold D, Jäggi A (2017): Impact of tracking loop settings of the Swarm GPS receiver on gravity field recovery. Advances in Space Research 59(12):2843-2854, DOI:10.1016/j.asr.2017.03.003

Mayer-Gürr T, Behzadpur S, Ellmer M, Kvas A, Klinger B, Strasser S, Zehentner N (2018): ITSGGrace2018 - Monthly, Daily and Static Gravity Field Solutions from GRACE. GFZ Data Services, DOI: 10.5880/ICGEM.2018.003 